\title{
A NEW LOW-COST DETECTION DEVICE FOR EARLY DISCRIMINATION OF EGGS FERTILITY USING ADVANCED STATISTICAL CLASSIFIERS
}

\author{
Said Elshahat Abdallah ${ }^{1}$, \\ Wael Mohamed Elmessery ${ }^{1}$ and Ahmed A. Elseify ${ }^{2}$
}

ABSTRACT

Detecting fertility methods of hatching eggs is getting an importance with the increase in poultry breeding facilities size to remove the nonhatchable eggs which consume time, space and cost without benefits. Early detection of the infertile eggs is a vital economic issue. Fertility detection methods are expensive to be applied widely, hence this investigation aimed to study the possibility of using a low-cost device as light dependent resistor sensors in detecting the fertility of hatching eggs with high efficient at candling process. Mathematical formulas were developed in this study to discriminate the fertile and infertile eggs by the light dependent resistor sensor and interfaced with a personal computer programmed by LabView software package to execute a certain control decision (is a hatchable egg or not?) via these formulas. Different statistical classifiers have been used to classify eggs into fertile and infertile eggs like linear, quadratic and partial least squares discriminant analyses and support vector machine. According to literature three different times were appointed at earlier times of egg incubation process for fertility identification investigation of $6^{\text {th }}, 9^{\text {th }}$ and $12^{\text {th }}$ day. For more identification precision, sensor position for light intensity measuring was investigated at three different measuring orientation lines against the investigated eggs at vertical, inclined $45^{\circ}$ and horizontal orientation line. Classification mathematical models were developed using the previous classifiers. Principal component and partial least squares regression were used to develop multiple linear regression models for each incubation period. determination

1. Associate Professor of Agricultural Process Engineering, Agricultural Engineering Department, Faculty of Agriculture, Kafrelsheikh University

2. M. Sc. Student, Agricultural Engineering Department, Faculty of Agriculture, Kafrelsheikh University 
It was found by the Principal Component Analysis, that the sensor orientation line position for light intensity measuring gives different measured values of the same investigated egg, but all these measurement values have an entirely correlation relationship with the classification efficiency. The highest identification rate of $97 \%$ obtained by the classifier of linear discriminant analysis at the $6^{\text {th }}$ day of the incubation period by the light dependent resistor sensor, which confirms the efficient use of this simple low-cost sensor in discrimination at earlier times of incubation period closing to the other sophisticated devices. The developed mathematical model can easily be implemented with Fuzzy logic controller; further research will be needed to accomplish the fully automated system.

Keywords: discrimination analysis, mathematical model, hatchability determination

\section{NOMENCLATURE}

\begin{tabular}{|c|c|c|c|}
\hline LDR & Light-Dependent Resistor & PCA & Principal Component Analysis \\
\hline LDA & $\begin{array}{l}\text { Linear Discriminant } \\
\text { Analysis }\end{array}$ & PCR & $\begin{array}{l}\text { Principal Component } \\
\text { Regression }\end{array}$ \\
\hline QDA & $\begin{array}{l}\text { Quadratic Discriminant } \\
\text { Analysis }\end{array}$ & PLS-R & $\begin{array}{l}\text { Partial Least Squares } \\
\text { Regression }\end{array}$ \\
\hline PLS-DA & $\begin{array}{l}\text { Partial Least Squares } \\
\text { Discriminant Analysis }\end{array}$ & $\begin{array}{l}\text { DAQ } \\
\mathrm{R}^{2}\end{array}$ & $\begin{array}{l}\text { Data Acquisition card } \\
\text { Coefficient of determination }\end{array}$ \\
\hline SVM & Support Vector Machine & LIFA & LabView Interface for Arduino \\
\hline $\mathrm{I}_{1}, \mathrm{I}_{2}$ and $\mathrm{I}_{3}$ & \multicolumn{3}{|c|}{$\begin{array}{l}\text { Light intensity measured from MOL positions 1, } 2 \text { and } 3 \text { respectively, } \\
\text { lux }\end{array}$} \\
\hline \multirow{2}{*}{$\mathrm{F}_{1}$ and $\mathrm{F}_{2}$} & \multirow{2}{*}{$\begin{array}{l}\text { First and second Principal } \\
\text { component, respectively }\end{array}$} & MOL & Measuring Orientation Line \\
\hline & & SD & Standard Deviation \\
\hline
\end{tabular}

\section{INTRODUCTION}

7 he biggest problem encounters the egg incubation industry is early fertility detection. The fertility detection requires higher sophisticated devices for that discrimination process. Infertile eggs can cause a bio-contamination if they were not removed before the setting into the artificial incubator or hatchers, in addition, taking time, 
space and costs (Smith et al., 2008; Zhu and Ma, 2011; Liu and Ngadi, 2013; Hai-ling et al., 2016 and Önler et al., 2017). As the egg fertility can be detected as possible at earlier times of the incubation duration gives a huge advantage to avoid the consequence problems. There is no devices till now can detect the egg fertility prior to the incubation process because, there is no physiological features of chick embryo can be clearly distinguished inside (Zhu and Ma, 2011). Most of egg incubation plants were tending to use destructive and candling analysis methods for egg fertility detection at 7 to 12 days of incubation investigated and developed by Cain et al. (1967); Howe et al. (1995); Akiyama et al. (1999); Tazawa et al. (1999); Moriya et al. (1999, 2000); Kato et al. (2002); Zhu and Ma (2011) and Liang et al. (2011) which is a difficult problem due to human faults and chick embryo handling effects. Hence, using those methods not are obtainable and reducing the hatching rates to be below the optimum rates of $86-95 \%$ according to USDA (2006). To overcome the problems associated to the destructive and candling analysis methods by human factor, there are many trials of automated nondestructive discrimination analysis methods for egg fertility detection at earlier times of incubation with advanced costly instruments such as machine vision (Zhu and Ma, 2011), Magnetic Resonance Imaging (MRI) (Klein et al., 2002; and Bain et al., 2007), acoustic resonant frequency (Coucke et al., 1997), acoustic impulse and supervised recognition (Lin et al., 2009), hyper spectral imaging (Jones et al., 2005; and Liu and Ngadi, 2013). Such those methods are complicated and expensive in general. Therefore, investigating the feasibility of using lowcost methods would be helpful for developing low-cost detecting fertility instruments. The need to a comprehensive detection method for picking out the infertile eggs one by one is an important issue that the present study dealt with. Egyptian traditional hatcheries, candling process is the most widely followed procedure for identifying fertility of hatching eggs in the early periods of egg incubation. Hatchery workers are using the Candler to observe egg content. Also they are placing egg in their eye socket to judge if it reached the proper temperature or not (FAO, 2009). Definitely, such those methods are not objective for judging hatchability of eggs because they depend on human experience. Hence, the research 
work is aiming to investigate the ability of using low-cost sensors such as Light-Dependent Resistor (LDR) to discriminate the eggs according to their fertility using different advanced statistical classifiers at earlier different ages of chick embryo to determine the highest percent of identification rate could be achieved by the classifier. The advanced classifiers are be used to develop a suitable mathematical model to allocate the eggs into a fertile or infertile group. There are many different statistical classifiers can be used for fertility detection of hatching eggs such as Linear Discriminant Analysis (LDA), Quadratic Discriminant Analysis (QDA), Partial Least Squares Discriminant Analysis (PLS-DA) and Support Vector Machine (SVM). SVM classifier was used before to classify the hatching eggs into fertile and infertile group and establishing a mathematical model by (Bhuvaneshwari and Scholar, 2015; Zhihui $\boldsymbol{e t}$ al., 2015 and Nurdiyah and Muwakhid, 2016). (Deng et al., 2010; Zhao et al., 2010 and Sun et al., 2017) also use SVM for eggshell cracks detection and identifying egg freshness and variety. Mathematical models generated by LDA, QDA and PLS-DA - are very useful to be included in low-cost detection devices of hatching eggs. LDA and PLSDA have been used by Yongwei et al. (2009) and Zhao et al. (2010) in identifying eggs quality attributes. Therefore the present investigation aims to investigate the following assignments:

1. Studying the feasibility of using low-cost sensors, such as LDR, to discriminate fertile and infertile eggs before hatching;

2. Determining the suitable statistical classifier method which gives the highest identification rate at earlier ages of chick embryo during incubation period; and

3. Developing a mathematical model could be used for automated system to determine if a new hatching egg is fertile or not.

\section{MATERIALS AND METHODS}

\section{Egg Samples and Physical Properties}

Egg samples of Hubbard broiler aging between 42-46 weeks old. Egg physical analysis was accomplished at the Faculty of Agriculture, Poultry Production Department, Ain Shams University by measuring external and 
internal dimensions of egg and yolk, mean shell thickness (of the three positions: at blunt, sharp ends and equator), weights of whole egg, albumen, yolk and wet and dry shell and the strength of eggshell. The instruments used for weighing are an electronic balance with a precision of $0.01 \mathrm{~g}$ and for eggshell thickness and breaking strength is a Vernier Caliper. All measurements and sampling were done at Tarek Diab Hatchery Plant, Nashil village, Qotour district, Gharbia Governorate, Egypt during the summer season of 2017. The freshly laid eggs were incubated in a Smart ${ }^{\mathrm{TM}}$ incubator (Pas Reform Hatchery Technologies, Zeddam, the Netherlands) at $37.6^{\circ} \mathrm{C}$ and $54 \%$ relative humidity, and were turned every one hour. On days of $6^{\text {th }}, 9^{\text {th }}$ and $12^{\text {th }}$ of incubation, eggs were taken out from the incubator to be candled. Candling process does not take more than two minutes to return eggs tray into the incubator immediately for chick embryos bio-security. Sampling was run at the periods of candling process at $6^{\text {th }}, 9^{\text {th }}$ and $12^{\text {th }}$ days of the incubation age. Total samples of 110 eggs are including 55 fertile and other of 55 infertile eggs.

\section{Experimental Setup}

To investigate the effectiveness of LDR in detecting fertility of hatching eggs and thus discriminate the fertile and infertile eggs, it needs an appropriate Candler which allows an easy and fast measuring of light intensity that is traveling from the light source to the sensor transmitting through the investigated eggs. A local-made Candler is consists of $70 \times$ $40 \times 30 \mathrm{~cm}$ container was manufactured from $3 \mathrm{~mm}$ mild steel sheets and furnished to be like a trolley for ease movement. The Candler was manufactured in a workshop located at Gharbia Governorate, Figure 1. At the predetermined investigated ages $\left(6^{\text {th }}, 9^{\text {th }}\right.$ and $12^{\text {th }}$ days $)$, the eggs tray was carried from the incubator and positioned on the Candler for light intensity measurements of light spectrum emitted from eggs during candling. Light source used for candling was a Light Emitting Diode (LED) lamp of $40 \mathrm{~W}$ and $2501 \mathrm{~m}$. Twelve lamps were uniformly distributed at the bottom of the container and were matched to be in three rows transversely and four columns longitudinally as depicted in Figure 1. Distance between lamps' top edges and eggs trays was of $8 \mathrm{~cm}$. For 
measuring light intensity, LDR sensor positioning was investigated at three different measuring orientation lines in space for giving the highest classification percent. The first, second and third sensor measuring orientation line was expressed as an angle, the angle between the sensor axis and egg axis of Zero, 45 and 90 degrees, respectively. LDR sensor was located in a transparent polyethylene container formed a shape of incomplete cone. The distance between the sensor and the container top is $1 \mathrm{~cm}$, Figure 2. For data acquiring from the LDR sensor, the microcontroller Arduino-Uno board was programmed as an interface Data Acquisition card (DAQ) module between the Personal Computer (PC) and LDR sensor. Arduino is a single-board microcontroller, can be used for reading data from sensors and also can use these data to control the overall system. So the Arduino-Uno board provides analog and digital Inputs and Outputs (I/O ports) to read data obtained from the sensor or giving orders for controlling. LabView software was used to program the Arduino microcontroller to be a DAQ card. LabView is graphical programming software. The interfacing between Arduino microcontroller and LabView is an innovative research tool due to the integration work between the open source microcontroller and PCs which gives higher potential tool for all biosystems monitoring and control operations. Data acquired by DAQ is processed, analyzed and presented graphically by LabView installed on the PC and this makes the programming modifications is available for any required duty. So LabView Interface for Arduino (LIFA) toolkit was used.

\section{LDR connection to Arduino DAQ}

Light intensity measurement was performed by a GL12528 12mm LDR sensor. LDR is an inexpensive cadmium sulfide photoconductive cell (Maranhão et al., 2015). Using resistance as a function of illumination, with the increase of illumination on the cell, resistance is going to decrease. Hence sensor output voltage is linearly proportional to illumination. The measurement range of illumination was provided by the manufacturer is from 0 to 10000lux with resistance range varying linearly from $1000 \mathrm{k} \Omega$ to $100 \Omega$, respectively. The LDR sensor has two terminals; the first terminal is connected to power supply terminal (5Volt $\left.\mathrm{V}_{\mathrm{cc}}\right)$ and 
the second one is output terminal $\left(\mathrm{V}_{\text {out }}\right)$ that gives the output voltage corresponding to the sensed illumination as shown in Figure 3.

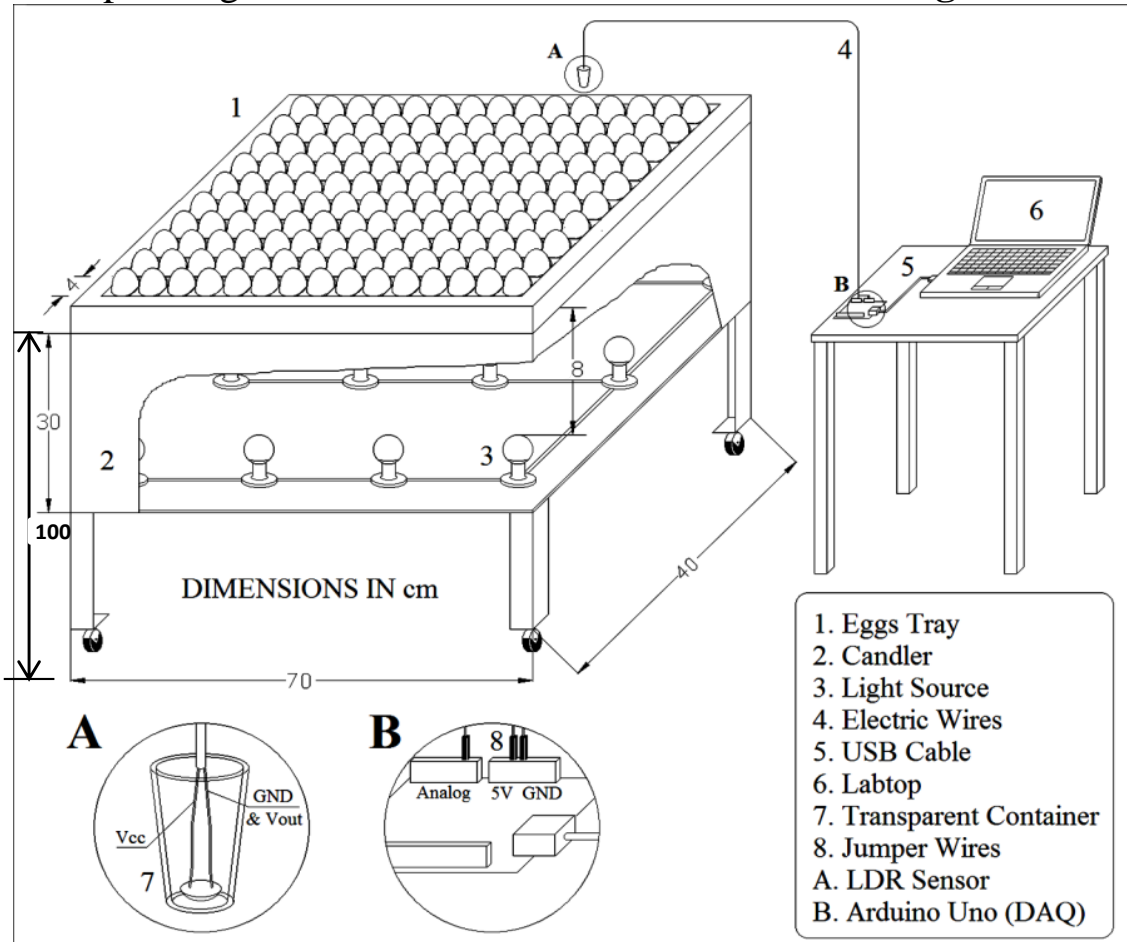

Figure 1. Schematic drawing of experimental setup used for investigating LDR efficiency in detecting fertility of hatching eggs

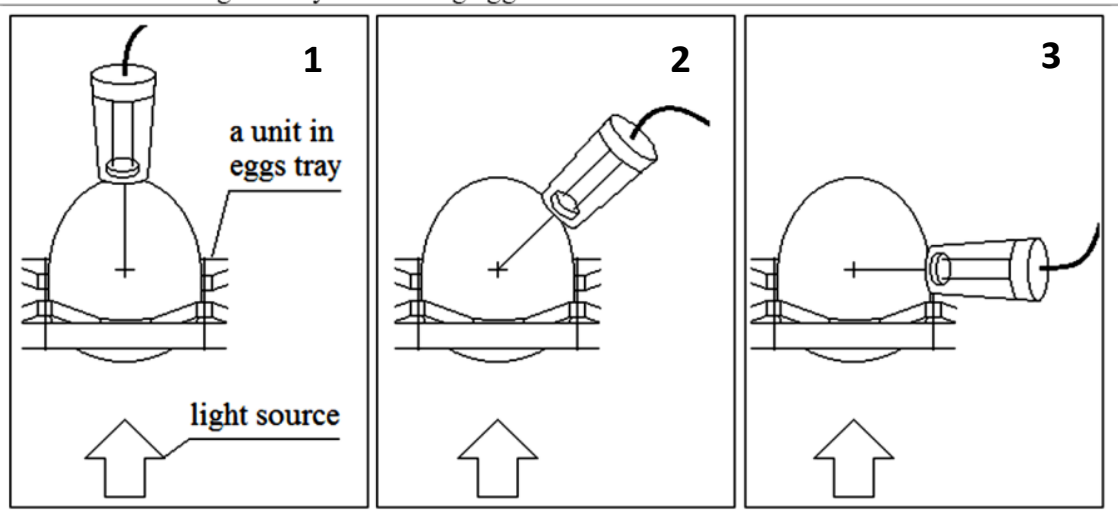

Figure 2. Schematic drawing of the three different positions that light intensity was measured from; (1) Zero degree, (2) 45 degrees and (3) 90 degrees

\section{Modeling and Simulation of Light Intensity Measuring System}

LabView 2013 software was used in the present investigation with NIVISA 5.0.3 software. LIFA toolkit was downloaded and installed from 
JKI VI Package Manager. So the microcontroller Arduino can be programmed and operated directly by LabView for any system controlling and data acquiring processes. For programming the DAQ (microcontroller Arduino) to acquire the data from LDR sensor, the front panel and block diagram of LabView software were used. In front panel, the indicators and controls for the programmer are appearing. Block diagram is containing the graphical source code. Hence any object on the front panel appears as a terminal on the block diagram (Johnson and Jennings, 2006). The programmed graphical code designed for this experiment was depicted in Figure 4. VISA resource was defined to use the COM4 of the PC for data communication and transfer via USB/Serial to the Arduino board; the baud rate was adjusted at $115200 \mathrm{baud} / \mathrm{second}$ for initialization. Analog input port ofA0 was chosen for data readings from the LDR sensor as shown in Figure 3. The while loop for the system continuous operation was timed at $1000 \mathrm{~ms}$ to take one reading every second, Figure 4. After coding the system, front panel would be as shown in Figure 5. Analog input was chosen from the front panel to be A0 and by running the system it would be able to measure light intensity emitted from eggshell in lux as depicted in Figure 5. LIFA toolkit has already been used in agricultural engineering applications by Faris and Mahmood (2014); and Pradeep et al. (2014).

\section{The effect of the measuring orientation line and PCA}

To study the effect of the measuring orientation line on discrimination precision; an adequate method was determined after a series of experiments to study the correlations between light intensity data and eggs fertility. Hence PCA technique was applied for this purpose. In PCA, light intensity measurements from both fertile and infertile eggs samples are presented by "loadings plots". Measured values of samples that are positively correlated to each other are close to each other. So it is expected that the infertile samples are going to be close to each other and the same for fertile samples, while loadings that are negatively correlated are going to be positioned opposite of each other. Hence it is expected that the infertile samples are going to be positioned opposite of the fertile ones. The three different measuring orientation lines and the measured values are going to be represented in "score plots". 


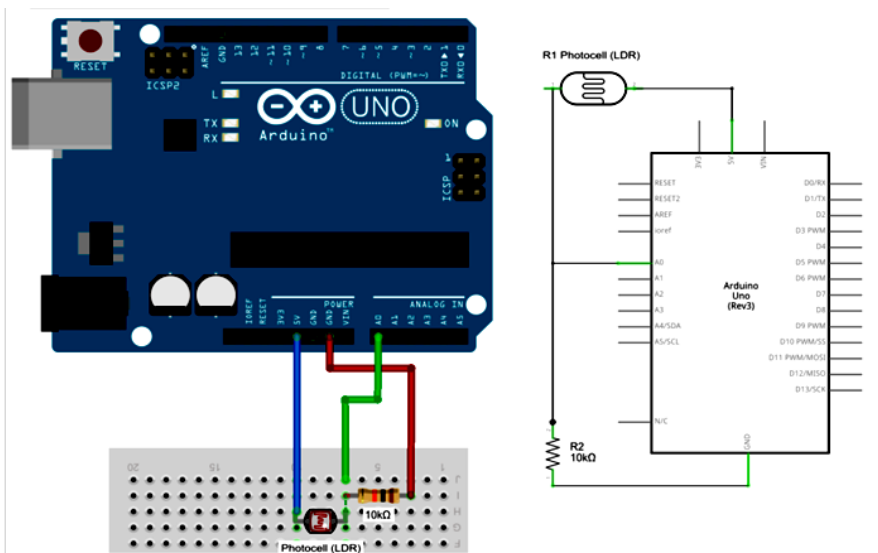

Figure 3. Schematic drawing of LDR circuit diagram and hardware system used for interfacing LDR sensor to Arduino for measuring light intensity

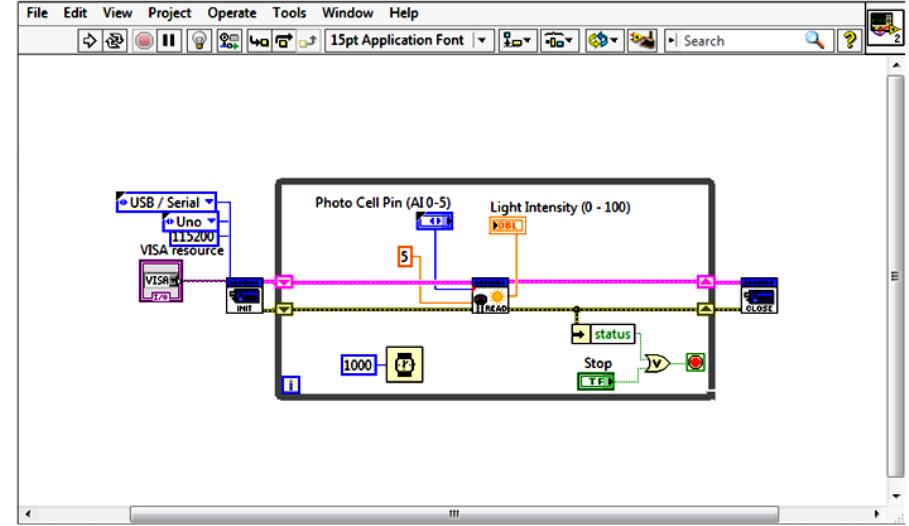

Figure 4. Block diagram of light intensity measurement code

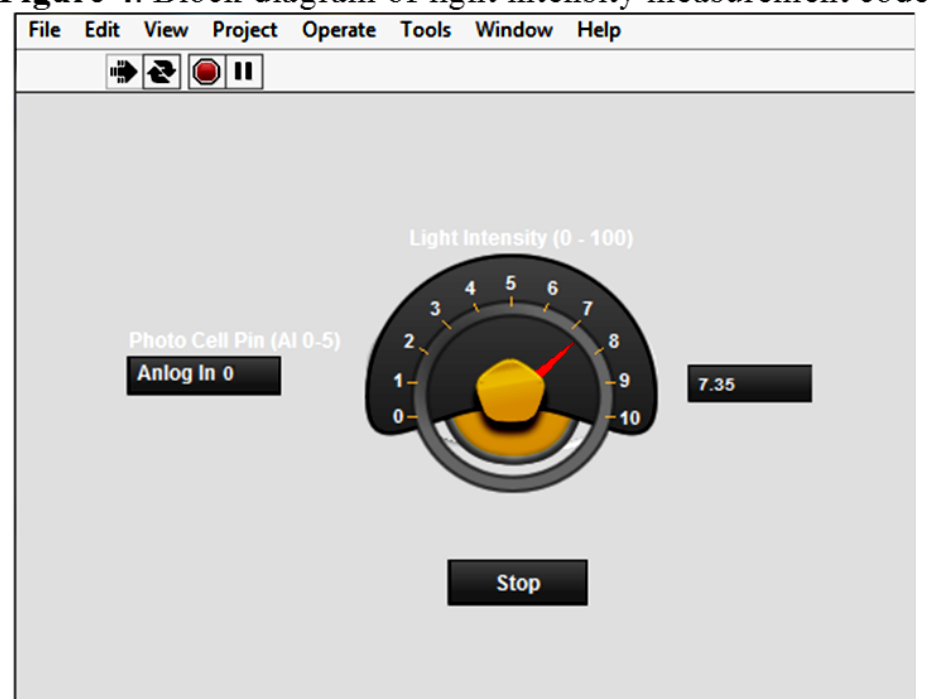

Figure 5. Front panel of light intensity measurement 
If there is a similarity in light intensity between any two measuring orientation lines, i.e., they are positively correlated, their scores are going to be close to each other. While if there are some kind of dissimilarity, i.e., they are negatively correlated, their scores are going to be positioned opposite to each other (Hopfer et al., 2014). PCA is obtaining to study if there are any differences between these orientation line positions of the sensor. XLSTAT 2017 software was used for PCA running.

\section{Classifiers and Classification Models}

To ensure if the data obtained from LDR sensor has the discrimination potential between fertile and infertile egg, different classifiers have been used for determining which one gave the highest percent of correctly classified samples. In addition, to make these data practical and applicable to be inserted in automated system for detecting fertility of hatching eggs. Classification models could be developed from these data in which two models are developed. One for fertile egg and the other for infertile and by substituting with light intensity value measured from the egg, fertility are going to be determined according to the model that gave the highest value between these two models. The statistical classifiers like LDA, QDA and PLS-DA were used for developing linear, multiple regression, second-order polynomial and interactive second-order polynomial models for predicting fertility. Also classifiers like SVM was used in the present study for finding support vectors and bias that could be used to find a boundary takes different shapes which could be used to differentiate between fertile and infertile eggs. LDA, QDA, PLS-DA and SVM have been used before in food science and engineering (Cen and He, 2007; Cocchi et al., 2006 and Elmessery and Abdallah, 2014). Also PCR and PLS-R were used for developing a classification model could be used via substituting in that model and then the sign of resulted value determine its fertility. For running this test, hundred samples was used as a training set; fifty fertile and the other fifty infertile and for validation set ten eggs was selected; five fertile and the other fives was infertile. Light intensity measured from infertile eggs was given a value of -1 and for fertile ones was given a value of +1 as a quantified value of its fertility. 


\section{RESULTS AND DISCUSSION}

From physical analysis results obtained and indicated at Table 1, there is no abnormal characteristics can influence hatchability and adequate production (Narushin and Romanov, 2002).

Table 1. Physical Properties of the investigated eggs

\begin{tabular}{|l|l|l|l|}
\hline Item & Mean \pm SD & Item & Mean \pm SD \\
\hline Egg weight, g & $65.75 \pm 3.42$ & Albumen height, mm & $9.87 \pm 2.27$ \\
\hline Length, mm & $56.82 \pm 2.1$ & Yolk diameter, mm & $41.21 \pm 1.03$ \\
\hline Width, mm & $46.4 \pm 2.11$ & Yolk weight, g & $19.9 \pm 0.96$ \\
\hline $\begin{array}{l}\text { Shell breaking } \\
\text { strength, N/cm }\end{array}$ & \multirow{2}{*}{$24 \pm 5.90$} & Shell wet-weight, g & $7.74 \pm 0.51$ \\
\cline { 2 - 4 } Yolk height, mm & $17.31 \pm 1.25$ & Shell dry-weight, g & $5.68 \pm 0.19$ \\
\hline
\end{tabular}

\section{Discrimination analysis by PCA method}

The main purpose of running Principal Component Analysis (PCA) is to find if there are any differences between the three different positions of Measuring Orientation Line (MOL) for light intensity measurements, Figure 2, and to find the correlation between fertility state and MOL positions. From PCA correlation matrix between light intensity value and the MOL positions of 1,2 and 3 as reported in Table 2 for each investigated age of eggs, it is evident from these results that the fertility has a high negative correlation between light intensity measured from MOL position 1 in each case of incubation period and the coefficient of correlation was of $-0.791,-0.840$ and -0.898 for the $6^{\text {th }}, 9^{\text {th }}$ and $12^{\text {th }}$ day of the incubation period, respectively. Also from PCA, the score plots are showing differences between light intensity values obtained from the three MOL positions. It is evident that MOL position 1 has a positive correlation with MOL position 2 according to the first component analysis because they were closely positioned at the quarter. This positive correlation between the two MOL positions 1 and 2 raises as incubation period increases as shown in Figure 6-C due to the increase of chick embryo size, this result has an important approach issue for chick embryo aging determination. Series of experiments will be required to deliver a scientific tool for embryo age measuring. Overall differences among light intensities measured at the three MOL positions which represent 56.20, 
74.87 and $50.02 \%$ for chick embryo at the $6^{\text {th }}, 9^{\text {th }}$ and $12^{\text {th }}$ day of incubation period, respectively as shown in Figure 6. The highest percent of $74.87 \%$ obtained at the $9^{\text {th }}$ day of the incubation period illustrates that there are high differences among light intensities measured from the three different MOL positions, Figure 6-B. Light intensity values measured from MOL positions 1 and 2 are very close to each other. For loading plots, it is evident there are differences between fertile and infertile eggs. The observations from 1 to 50 (Obs1 to Obs50) and from 51 to 100 (Obs51 to Obs100) were infertile and fertile eggs, respectively.

Table 2. Correlation matrixes between light intensity measured from the three different MOL positions and fertility for each investigated incubation period

\begin{tabular}{|c|c|c|c|c|c|}
\hline \multirow{5}{*}{$\begin{array}{l}6 \text { days of } \\
\text { incubation } \\
\text { period }\end{array}$} & Variables & Position 1 & Position 2 & Position 3 & Fertility \\
\hline & Position 1 & 1.000 & 0.460 & 0.200 & -0.791 \\
\hline & Position 2 & 0.460 & 1.000 & 0.353 & -0.432 \\
\hline & Position 3 & 0.200 & 0.353 & 1.000 & -0.093 \\
\hline & Fertility & -0.791 & -0.432 & -0.093 & 1.000 \\
\hline \multirow{5}{*}{$\begin{array}{l}9 \text { days of } \\
\text { incubation } \\
\text { period }\end{array}$} & Variables & Position 1 & Position 2 & Position 3 & Fertility \\
\hline & Position 1 & 1.000 & 0.857 & 0.391 & -0.840 \\
\hline & Position 2 & 0.857 & 1.000 & 0.590 & -0.640 \\
\hline & Position 3 & 0.391 & 0.590 & 1.000 & -0.068 \\
\hline & Fertility & -0.840 & -0.640 & -0.068 & 1.000 \\
\hline \multirow{5}{*}{$\begin{array}{l}12 \text { days of } \\
\text { incubation } \\
\text { period }\end{array}$} & Variables & Position 1 & Position 2 & Position 3 & Fertility \\
\hline & Position 1 & 1.000 & 0.452 & 0.129 & -0.898 \\
\hline & Position 2 & 0.452 & 1.000 & 0.092 & -0.507 \\
\hline & Position 3 & 0.129 & 0.092 & 1.000 & -0.114 \\
\hline & Fertility & -0.898 & -0.507 & -0.114 & 1.000 \\
\hline
\end{tabular}

\section{Regression analysis by PCR and PLS-R methods}

PCR and PLS-R were used to develop a linear equation fitting the data obtained from the three MOL positions of the fertility eggs, Equation 1. By substituting light intensity values in this equation; if the result value is negative the egg be infertile, otherwise be fertile. The model constants for Equation 1 have been listed in Table 3 for both PCR and PLS-R methods.

$$
\text { Fertility }=a+b I_{1}+c I_{2}+d I_{3}
$$

Eqn 1

Where $I_{1}, I_{2}$ and $I_{3}$ are light intensity measured from positions 1, 2 and 3, respectively. It was noticed that with the increase in chick embryo age the 
model fitness is increased. The mathematical model developed by PCR has higher coefficient of determination than PLS-R at all incubation ages and the highest value obtained of the coefficient of determination obtained is 0.819 at age of 12 days.

\section{loading plots}
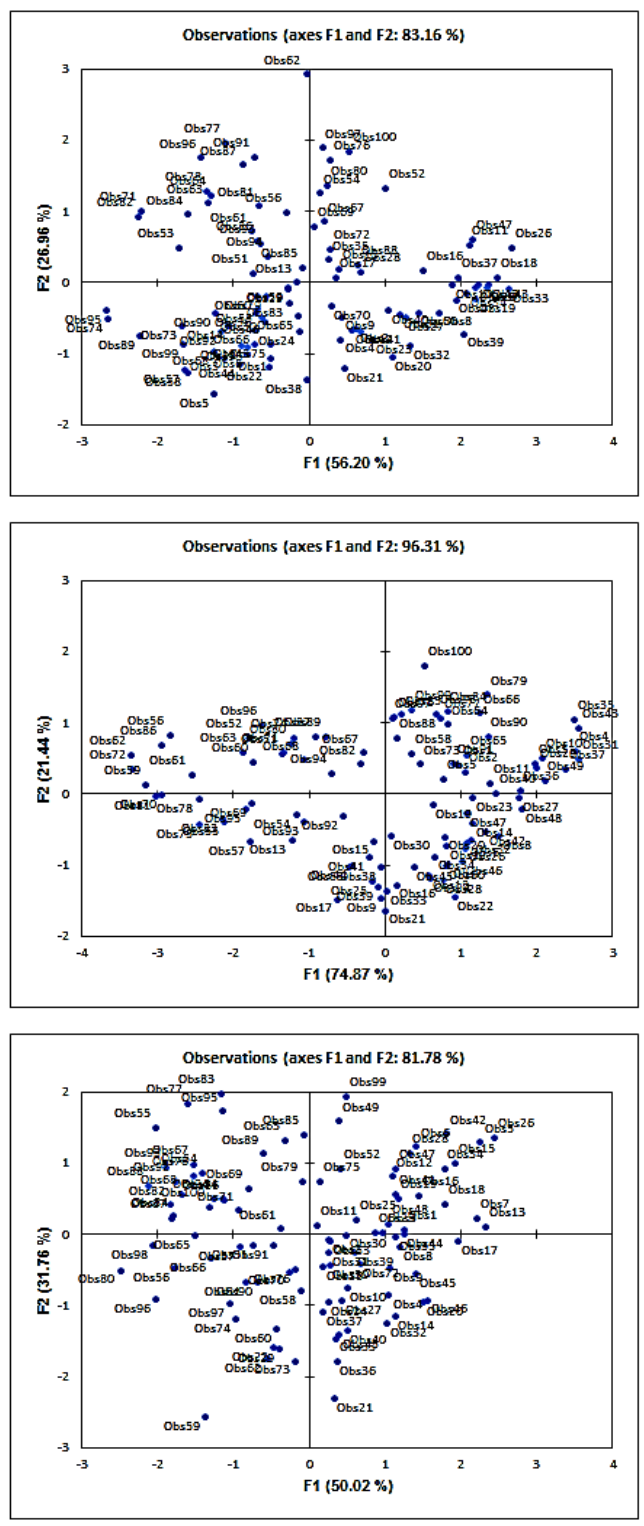

score plots

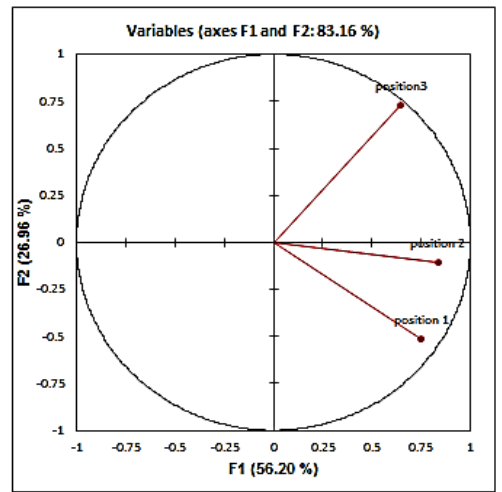

A
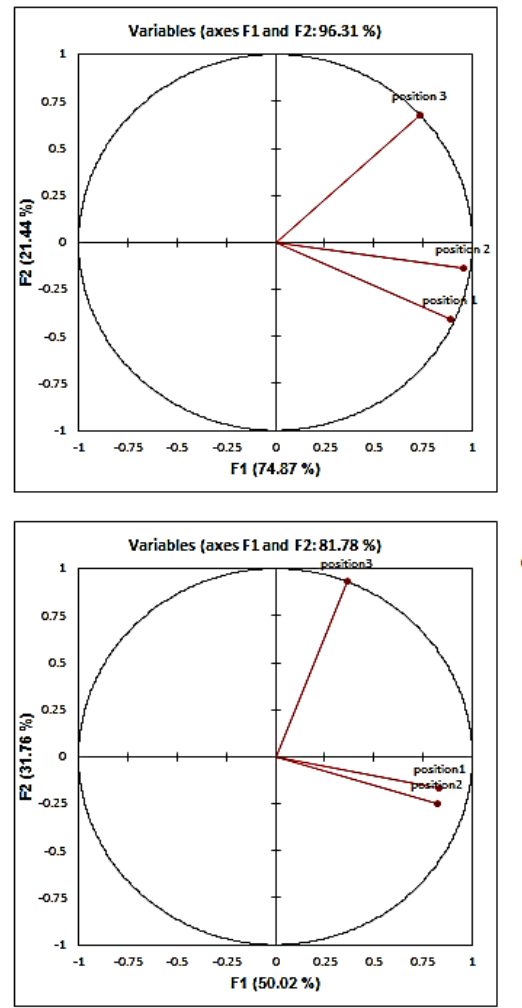

Figure 6. Loading plots and score plots of PCA results for each age of chick embryo at (A) 6, (B) 9 and (C) 12 days old 
Table 3. Fertility predicting mathematical model constants for PCR and PLS-R methods

\begin{tabular}{|c|c|c|c|c|c|c|}
\hline \multirow{2}{*}{$\begin{array}{c}\text { Classification } \\
\text { method }\end{array}$} & $\begin{array}{c}\text { Incubation } \\
\text { period, } \\
\text { days }\end{array}$ & \multicolumn{4}{|c|}{ Model constants } & \multirow{2}{*}{$\mathrm{R}^{2}$} \\
\cline { 3 - 7 } & 6 & 5.784 & -0.102 & -0.028 & 0.027 & 0.640 \\
\hline \multirow{3}{*}{ PCR } & 9 & 1.280 & -0.147 & 0.001 & 0.082 & 0.786 \\
\cline { 2 - 7 } & 12 & 4.648 & -0.084 & -0.017 & 0.001 & 0.819 \\
\cline { 2 - 7 } & 6 & 11.087 & -0.074 & -0.070 & -0.018 & 0.565 \\
\hline \multirow{3}{*}{ PLS-R } & 9 & 8.942 & -0.067 & -0.058 & -0.010 & 0.587 \\
\cline { 2 - 7 } & 12 & 7.061 & -0.063 & -0.048 & -0.015 & 0.760 \\
\hline
\end{tabular}

Identification Rates of PLS-DA, QDA, LDA and SVM Classifiers

The feasibility of using LDR sensor to achieve high percentage of identification rate in which eggs samples were classified correctly into fertile and infertile eggs. The percentages of correctly classified observations were listed, for all classifiers used in the present study, in Table 4. According to LDA classifier the data measured from each individual MOL position have higher identification rate than by QDA, where the MOL position 1 achieves the highest identification rate by LDA at chick embryo age of 6 days old of $95 \%$ for training set. But, for MOL positions 2 and 3, the identification rates were lower. In case of using the three MOL positions in the training set, classification at age of 6 days old was correctly classified of $97 \%$ by LDA and $95 \%$ by QDA. The validation set was $100 \%$ correctly classified by both classifiers LDA and QDA. For an early fertility detection of hatching egg, light intensity should be measured from MOL positions of 1,2 and 3 and data obtained should be classified according to LDA. For simple or quick detection, light intensity can be measured at MOL position 1, and age of 12 days old of chick embryo. Using QDA classifier it is of course an advanced level of chick embryo development, so it is not recommended. PLS-DA classifier gave the lowest percentage of correct classification of eggs at each chick embryo age among other statistical classifiers at the three MOL positions, Table 5. To compare Radial Basis Function, RBF-SVM classifier results obtained by this study and the other done by Zhu and Ma (2011); RBF kernel classifier achieves the percent of $92 \%$ at training set among the other three types of kernel classifier of SVM at the age of 6 days old of chick embryo, but the validation set present of the three types 
of kernels was $100 \%$. However the investigation done by Zhu and Ma (2011) obtains higher identification rate of $95.8 \%$ for training set by linear kernel with the machine vision for eggs were investigated in the period from $7^{\text {th }}$ to $12^{\text {th }}$ day of the incubation and $99.1 \%$ by RBF kernel. But on the other hand in this study, the classifiers of LDA, QDA and PLS-DA with LDR sensor achieve the percent of 97, 95, and $85 \%$ of training set at $6^{\text {th }}$ day for the three MOL positions, respectively, Table 5. This confirms that the simple low-cost LDR sensor can classify eggs according to their fertility as well as machine vision system does.

\section{Classification Mathematical Models}

The main purpose of using classifiers is to find a suitable mathematical model could be used for fertility predicting of an egg by substituting the value of light intensity in two models, i.e., a model for fertile eggs and the other for infertile ones. In comparison between the result values of the two models, the highest result value obtained determines its fertility. Hence the mathematical models have been developed by those classifiers studied above that can be included in any automated control system such as Fuzzy logic control system for sorting eggs according to their fertility. Table 6 shows the overall model constant values for all measured values of light intensity obtained from the three MOL positions together. On the other hand, Table 7 illustrates the constant values of the simple model which depends only on one position of MOL to measure light intensity of the egg. After that Equations 2 and $\mathbf{4}$ would be used for discrimination process. These equations were generated using LDA and QDA. In case of using three MOL positions, Equations 3 and 5 would be used including multiple linear regression model and interactive second-order polynomial model. The previously mentioned models were developed also for each age of incubation period and by them any automated system could detect the hatching egg fertility. Because of the shortage of time and space, list of SVM for RBF kernel was reported only because its highest performance in discriminating the eggs at 6 days old of chick embryo, Table 8. The list of SVM and their bias for each age of chick embryo to make a boundary separates between measured values of light intensity from fertile and infertile eggs could be used in classifying eggs according to its fertility and for further research on it in the future. 
Table 4. Identification rate of LDA and QDA classifiers according to chick embryo age and one identical MOL position on the egg

\begin{tabular}{|c|c|c|c|c|c|c|c|c|c|c|c|c|c|}
\hline \multirow{4}{*}{$\begin{array}{c}\text { Measuring } \\
\text { Position }\end{array}$} & \multirow{4}{*}{$\begin{array}{l}\text { Incubation } \\
\text { period, } \\
\text { days }\end{array}$} & \multicolumn{12}{|c|}{ Correctly classified observations by different classifiers, $\%$} \\
\hline & & \multicolumn{6}{|c|}{ Linear Discriminant Analysis } & \multicolumn{6}{|c|}{ Quadratic Discriminant Analysis } \\
\hline & & \multicolumn{3}{|c|}{ Training set } & \multicolumn{3}{|c|}{ Validation set } & \multicolumn{3}{|c|}{ Training set } & \multicolumn{3}{|c|}{ Validation set } \\
\hline & & Fertile & Infertile & Total & Fertile & Infertile & Total & Fertile & Infertile & Total & Fertile & Infertile & Total \\
\hline \multirow{3}{*}{ Position 1} & 6 & 94.00 & 96.00 & 95.00 & 100.00 & 100.00 & 100.00 & 98.00 & 90.00 & 94.00 & 100.00 & 100.00 & 100.00 \\
\hline & 9 & 88.00 & 98.00 & 93.00 & 100.00 & 100.00 & 100.00 & 94.00 & 96.00 & 95.00 & 100.00 & 100.00 & 100.00 \\
\hline & 12 & 100.00 & 96.00 & 98.00 & 100.00 & 100.00 & 100.00 & 100.00 & 100.00 & 100.00 & 100.00 & 100.00 & 100.00 \\
\hline \multirow{3}{*}{ Position 2} & 6 & 60.00 & 64.00 & 62.00 & 60.00 & 60.00 & 60.00 & 58.00 & 68.00 & 63.00 & 60.00 & 80.00 & 70.00 \\
\hline & 9 & 68.00 & 86.00 & 77.00 & 80.00 & 100.00 & 90.00 & 66.00 & 86.00 & 76.00 & 80.00 & 100.00 & 90.00 \\
\hline & 12 & 62.00 & 80.00 & 71.00 & 80.00 & 100.00 & 90.00 & 62.00 & 86.00 & 74.00 & 80.00 & 100.00 & 90.00 \\
\hline \multirow{3}{*}{ Position 3} & 6 & 54.00 & 52.00 & 53.00 & 40.00 & 40.00 & 40.00 & 38.00 & 68.00 & 53.00 & 20.00 & 40.00 & 30.00 \\
\hline & 9 & 54.00 & 48.00 & 51.00 & 100.00 & 40.00 & 70.00 & 54.00 & 50.00 & 52.00 & 100.00 & 40.00 & 70.00 \\
\hline & 12 & 52.00 & 54.00 & 53.00 & 80.00 & 20.00 & 50.00 & 70.00 & 42.00 & 56.00 & 80.00 & 20.00 & 50.00 \\
\hline
\end{tabular}


Table 5. Identification rate of each classifier according to chick embryo age and the whole three MOL positions on the egg

\begin{tabular}{|c|c|c|c|c|c|c|c|c|c|c|c|c|c|}
\hline \multirow{4}{*}{$\begin{array}{c}\text { Measuring } \\
\text { Position }\end{array}$} & \multirow{4}{*}{$\begin{array}{c}\text { Incubation } \\
\text { period, } \\
\text { day }\end{array}$} & \multicolumn{12}{|c|}{ Correctly classified observations by different classifiers, $\%$} \\
\hline & & \multicolumn{6}{|c|}{ Linear Discriminant Analysis } & \multicolumn{6}{|c|}{ Quadratic Discriminant Analysis } \\
\hline & & \multicolumn{3}{|c|}{ Training set } & \multicolumn{3}{|c|}{ Validation set } & \multicolumn{3}{|c|}{ Training set } & \multicolumn{3}{|c|}{ Validation set } \\
\hline & & Fertile & Infertile & Total & Fertile & Infertile & Total & Fertile & Infertile & Total & Fertile & Infertile & Total \\
\hline \multirow{15}{*}{$\begin{array}{c}\text { Whole } \\
\text { MOL } \\
\text { Positions } \\
\text { of } 1,2 \text { and } \\
3\end{array}$} & 6 & 96.00 & 98.00 & 97.00 & 100.00 & 100.00 & 100.00 & 92.00 & 98.00 & 95.00 & 100.00 & 100.00 & 100.00 \\
\hline & 9 & 90.00 & 98.00 & 94.00 & 100.00 & 100.00 & 100.00 & 98.00 & 96.00 & 97.00 & 100.00 & 100.00 & 100.00 \\
\hline & 12 & 100.00 & 100.00 & 100.00 & 100.00 & 100.00 & 100.00 & 100.00 & 100.00 & 100.00 & 100.00 & 100.00 & 100.00 \\
\hline & & \multicolumn{6}{|c|}{ Partial Least Squares Discriminant Analysis } & \multicolumn{6}{|c|}{ Support Vector Machine (Linear kernel) } \\
\hline & & \multicolumn{3}{|c|}{ Training set } & \multicolumn{3}{|c|}{ Validation set } & \multicolumn{3}{|c|}{ Training set } & \multicolumn{3}{|c|}{ Validation set } \\
\hline & & Fertile & Infertile & Total & Fertile & Infertile & Total & Fertile & Infertile & Total & Fertile & Infertile & Total \\
\hline & 6 & 94.00 & 76.00 & 85.00 & 100.00 & 80.00 & 90.00 & 98.00 & 80.00 & 89.00 & 100.00 & 100.00 & 100.00 \\
\hline & 9 & 76.00 & 98.00 & 87.00 & 100.00 & 100.00 & 100.00 & 94.00 & 98.00 & 96.00 & 100.00 & 100.00 & 100.00 \\
\hline & 12 & 96.00 & 96.00 & 96.00 & 100.00 & 100.00 & 100.00 & 100.00 & 98.00 & 99.00 & 100.00 & 100.00 & 100.00 \\
\hline & & \multicolumn{6}{|c|}{ Support Vector Machine (Power kernel) } & \multicolumn{6}{|c|}{ Support Vector Machine (RBF kernel) } \\
\hline & & \multicolumn{3}{|c|}{ Training set } & \multicolumn{3}{|c|}{ Validation set } & \multicolumn{3}{|c|}{ Training set } & \multicolumn{3}{|c|}{ Validation set } \\
\hline & & Fertile & Infertile & Total & Fertile & Infertile & Total & Fertile & Infertile & Total & Fertile & Infertile & Total \\
\hline & 6 & 98.00 & 80.00 & 89.00 & 100.00 & 100.00 & 100.00 & 100.00 & 84.00 & 92.00 & 100.00 & 100.00 & 100.00 \\
\hline & 9 & 94.00 & 98.00 & 96.00 & 100.00 & 100.00 & 100.00 & 94.00 & 96.00 & 95.00 & 100.00 & 100.00 & 100.00 \\
\hline & 12 & 100.00 & 98.00 & 99.00 & 100.00 & 100.00 & 100.00 & 100.00 & 98.00 & 99.00 & 100.00 & 100.00 & 100.00 \\
\hline
\end{tabular}




\section{CONCLUSIONS}

In the present study the discrimination efficiency of a low-cost device for fertility early detection of hatching eggs has been investigated. Mathematical models to discriminate the fertile eggs were developed using different advanced statistical classifiers. Based on the research work described here, it is possible to release the following conclusions:

1. By using PCA the differences between light intensity values obtained from the first two measuring orientation line positions on the egg fertility discrimination which are going to decrease with the increase of chick embryo age.

2. The mathematical models developed by the classifier of LDA, QDA and PLS-DA can successfully early discriminate the fertile eggs at $6^{\text {th }}$ day of the incubation process based on the whole data obtained from the three MOL positions together was 97, 95 and $85 \%$ for the training set, respectively.

3. SVM classifier which was widely used for egg fertility discrimination with machine visions can discriminate egg fertility in the present study with LDR sensor according to its fertility with an identification rate of training set 89,89 and $92 \%$ for 6 days of incubation for three types of the sub classifiers of linear, power and RBF kernel, respectively the validation set identification rate reached $100 \%$ for each method of SVM.

4. Simple sensors like LDR are efficient to detect fertility of hatching eggs using Candlers and could be used for Fuzzy logic automated system using the mathematical formulas developed in the present study.

5. Mathematical models (Equations 3 and 5) developed by LDA and QDA classifiers can precisely discriminate the fertile eggs using the constants which are indicated at Table 6. By substituting the light intensities obtained by low-cost Light-Dependent Resistor (LDR) in the developed equation of fertile part of equation 3 or 5 , if the result is +1 means that the egg is fertile and as the same by substituting the light intensities in the infertile part of equation 3 or 5 , if the result is -1 indicates that the egg is infertile. 
Table 6. Developed general form of classification models used for eggs discrimination according to their fertility

\begin{tabular}{|c|c|c|c|c|c|}
\hline \multicolumn{6}{|c|}{ Model type in case of measuring from: } \\
\hline \multicolumn{3}{|c|}{ MOL position 1} & \multicolumn{3}{|l|}{ MOL positions of 1,2 and 3} \\
\hline \multicolumn{3}{|c|}{ Linear regression } & \multicolumn{3}{|l|}{ Multiple linear regression } \\
\hline $\begin{array}{l}f=a+b I_{1} \\
n=a+b I_{1}\end{array}$ & \} & Eqn 2 & $\begin{array}{l}f=a+b I_{1}+c I_{2}+d I_{3}(\text { fertile part }) \\
n=a+b I_{1}+c I_{2}+d I_{3}(\text { infertile part })\end{array}$ & \} & Eqn 3 \\
\hline \multicolumn{3}{|c|}{ Second-order polynomial } & \multicolumn{3}{|l|}{ Interactive second-order polynomial } \\
\hline $\begin{array}{l}f=a+b I_{1}+c I_{1}^{2} \\
n=a+b I_{1}+c I_{1}\end{array}$ & & Eqn 4 & $\begin{array}{l}f=a+b I_{1}+c I_{2}+d I_{3}+e I_{1}^{2}+f I_{1} I_{2}+g I_{1} I_{3}+h I_{2}^{2}+i I_{2} I_{3}+j I_{3}^{2} \\
n=a+b I_{1}+c I_{2}+d I_{3}+e I_{1}^{2}+f I_{1} I_{2}+g I_{1} I_{3}+h I_{2}^{2}+i I_{2} I_{3}+j I_{3}^{2}\end{array}$ & \} & Eqn 5 \\
\hline
\end{tabular}

Table 7.Classification mathematical models constants of higher identification rate classifier Predicting models need to measure light intensity from positions 1,2 and 3

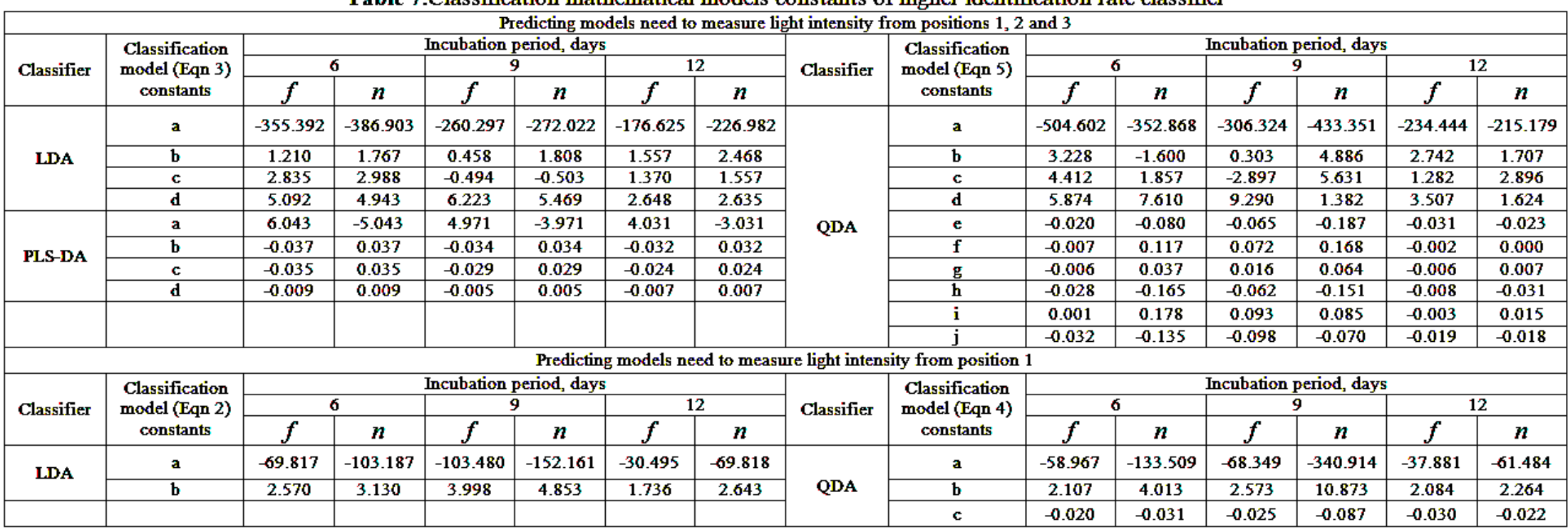


Table 8. List of support vectors and bias for each incubation period using RBF kernel

\begin{tabular}{|c|c|c|c|c|c|c|c|c|c|c|c|c|c|c|c|}
\hline \multirow{5}{*}{ S.N. } & \multicolumn{15}{|c|}{ Support vectors (RBF kernel) } \\
\hline & \multicolumn{15}{|c|}{ Incubation period, day } \\
\hline & \multicolumn{5}{|c|}{$6(\mathrm{Bias}=-0.743)$} & \multicolumn{5}{|c|}{$9($ Bias $=0.094)$} & \multicolumn{5}{|c|}{$12($ Bias $=-0.464)$} \\
\hline & \multirow[b]{2}{*}{ Fertility } & \multirow[b]{2}{*}{ alpha } & \multicolumn{3}{|c|}{ Light intensity, lux } & \multirow[b]{2}{*}{ Fertility } & \multirow[b]{2}{*}{ alpha } & \multicolumn{3}{|c|}{ Light intensity, lux } & \multirow[b]{2}{*}{ Fertility } & \multirow[b]{2}{*}{ alpha } & \multicolumn{3}{|c|}{ Light intensity, lux } \\
\hline & & & $\begin{array}{c}\text { Position } \\
1\end{array}$ & $\begin{array}{c}\text { Position } \\
2 \\
\end{array}$ & $\begin{array}{c}\text { Position } \\
3 \\
\end{array}$ & & & $\begin{array}{c}\text { Position } \\
1\end{array}$ & $\begin{array}{c}\text { Position } \\
2\end{array}$ & $\begin{array}{c}\text { Position } \\
3 \\
\end{array}$ & & & $\begin{array}{c}\text { Position } \\
1 \\
\end{array}$ & $\begin{array}{c}\text { Position } \\
2 \\
\end{array}$ & $\begin{array}{c}\text { Position } \\
3 \\
\end{array}$ \\
\hline 1 & -1 & 1.000 & 0.693 & 0.506 & 0.237 & -1 & 1.000 & 0.626 & 0.850 & 0.614 & -1 & 1.000 & 0.708 & 0.551 & 0.573 \\
\hline 2 & -1 & 1.000 & 0.699 & 0.272 & 0.211 & -1 & 1.000 & 0.732 & 0.776 & 0.629 & -1 & 1.000 & 0.570 & 0.593 & 0.611 \\
\hline 3 & -1 & 1.000 & 0.654 & 0.840 & 0.329 & -1 & 1.000 & 0.740 & 0.682 & 0.586 & -1 & 1.000 & 0.664 & 0.754 & 0.809 \\
\hline 4 & -1 & 1.000 & 0.667 & 0.383 & 0.053 & -1 & 0.854 & 0.886 & 0.916 & 0.814 & -1 & 1.000 & 0.542 & 0.605 & 0.237 \\
\hline 5 & -1 & 1.000 & 0.595 & 0.519 & 0.184 & -1 & 1.000 & 0.821 & 0.822 & 0.643 & -1 & 1.000 & 0.691 & 0.647 & 0.656 \\
\hline 6 & -1 & 1.000 & 0.719 & 0.679 & 0.447 & -1 & 1.000 & 0.528 & 0.393 & 0.129 & -1 & 1.000 & 0.586 & 0.778 & 0.427 \\
\hline 7 & -1 & 1.000 & 0.810 & 0.938 & 0.842 & -1 & 1.000 & 0.715 & 0.561 & 0.271 & -1 & 1.000 & 0.586 & 0.599 & 0.237 \\
\hline 8 & -1 & 1.000 & 0.588 & 0.469 & 0.211 & -1 & 1.000 & 0.715 & 0.561 & 0.014 & -1 & 0.791 & 0.708 & 0.611 & 0.603 \\
\hline 9 & -1 & 1.000 & 0.575 & 0.556 & 0.474 & -1 & 1.000 & 0.846 & 0.579 & 0.514 & -1 & 1.000 & 0.641 & 0.623 & 0.542 \\
\hline 10 & -1 & 1.000 & 0.614 & 0.309 & 0.289 & -1 & 1.000 & 0.789 & 0.822 & 0.557 & -1 & 0.270 & 0.713 & 0.904 & 0.878 \\
\hline 11 & -1 & 1.000 & 0.706 & 0.531 & 0.618 & -1 & 1.000 & 0.740 & 0.598 & 0.314 & -1 & 1.000 & 0.686 & 0.641 & 0.374 \\
\hline 12 & -1 & 0.339 & 0.771 & 0.852 & 0.697 & -1 & 1.000 & 0.911 & 0.925 & 1.000 & -1 & 1.000 & 0.564 & 0.677 & 0.504 \\
\hline 13 & -1 & 1.000 & 0.647 & 0.630 & 0.553 & -1 & 0.807 & 0.732 & 0.654 & 0.186 & -1 & 1.000 & 0.537 & 0.802 & 0.573 \\
\hline 14 & -1 & 1.000 & 0.660 & 0.568 & 0.184 & -1 & 1.000 & 0.797 & 0.907 & 0.600 & -1 & 1.000 & 0.636 & 0.491 & 0.908 \\
\hline 15 & -1 & 1.000 & 0.752 & 0.481 & 0.382 & -1 & 1.000 & 0.707 & 0.598 & 0.200 & -1 & 1.000 & 0.702 & 0.593 & 0.504 \\
\hline 16 & -1 & 1.000 & 0.673 & 0.691 & 0.605 & -1 & 1.000 & 0.951 & 0.925 & 0.986 & 1 & 1.000 & 0.426 & 0.485 & 0.504 \\
\hline 17 & -1 & 1.000 & 0.686 & 0.383 & 0.500 & -1 & 1.000 & 0.683 & 0.570 & 0.143 & 1 & 1.000 & 0.443 & 0.766 & 0.588 \\
\hline 18 & -1 & 1.000 & 0.588 & 0.481 & 0.329 & 1 & 1.000 & 0.537 & 0.738 & 0.086 & 1 & 0.935 & 0.432 & 0.204 & 0.366 \\
\hline 19 & -1 & 1.000 & 0.601 & 0.605 & 0.592 & 1 & 1.000 & 0.569 & 0.290 & 0.243 & 1 & 1.000 & 0.388 & 0.467 & 0.489 \\
\hline 20 & -1 & 1.000 & 0.595 & 0.432 & 0.342 & 1 & 1.000 & 0.463 & 0.280 & 0.057 & 1 & 1.000 & 0.421 & 0.737 & 0.427 \\
\hline 21 & -1 & 1.000 & 0.732 & 0.691 & 0.197 & 1 & 1.000 & 0.634 & 0.579 & 0.614 & 1 & 1.000 & 0.448 & 0.665 & 0.298 \\
\hline 22 & -1 & 1.000 & 0.627 & 0.469 & 0.158 & 1 & 1.000 & 0.626 & 0.682 & 0.757 & 1 & 1.000 & 0.454 & 0.551 & 0.573 \\
\hline 23 & -1 & 1.000 & 0.562 & 0.568 & 0.211 & 1 & 1.000 & 0.707 & 0.766 & 0.686 & 1 & 1.000 & 0.355 & 0.743 & 0.214 \\
\hline 24 & -1 & 1.000 & 0.588 & 0.506 & 0.316 & 1 & 1.000 & 0.618 & 0.813 & 0.829 & 1 & 1.000 & 0.421 & 0.341 & 0.427 \\
\hline 25 & -1 & 1.000 & 0.765 & 1.000 & 0.842 & 1 & 1.000 & 0.528 & 0.785 & 0.543 & 1 & 1.000 & 0.393 & 0.952 & 0.557 \\
\hline
\end{tabular}


To be continued Table 8

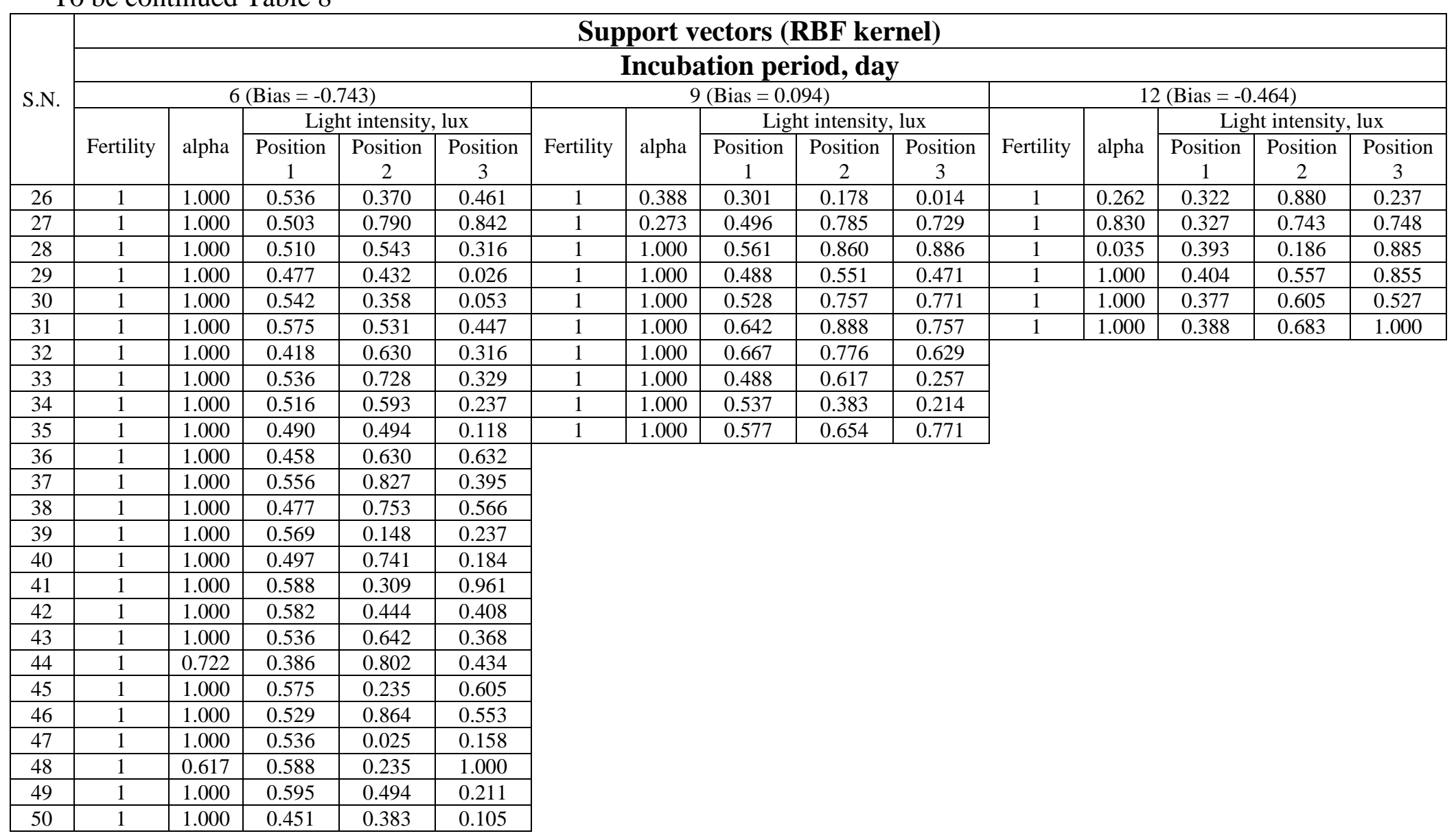


PROCESS ENGINEERING

\section{REFERENCES}

Akiyama, R.; H. Mitsubayashi; H. Tazawa and W. W. Burggren. 1999. Heart rate responses to altered ambient oxygen in early (days 3-9) chick embryos in the intact egg. Journal of Comparative Physiology B, 169(2): 85-92.

Bain, M. M.; A. J. Fagan; J. M. Mullin; I. McNaught and B. Condon. 2007. Monitoring chick development in ovo from 12 days incubation through to hatching by magnetic resonance imaging (MRI). Journal of Magnetic Resonance Imaging, 26: 198-201.

Bhuvaneshwari, M. M. and P. G. Scholar. 2015. Improvement in detection of chicken egg fertility using image processing techniques. International Journal on Engineering Technology and Sciences, 2(4): 64-67.

Cain, J. R.; U. K. Abbott and V. L. Rogallo. 1967. Heart rate of the developing chick embryo. Experimental Biology and Medicine, 126(2): 507-510.

Cen, H. and Y. He. 2007. Theory and application of near infrared reflectance spectroscopy in determination of food quality. Trends in Food Science \& Technology, 18(2): 72-83.

Cocchi, M.; C. Durante; G. Foca; A. Marchetti; L.Tassi and A. Ulrici. 2006. Durum wheat adulteration detection by NIR spectroscopy multivariate calibration. Talanta, 68(5): 1505-1511.

Coucke, P. M.; G. M. Room; E. M. Decuypere and J. G. De Baerdemaeker. 1997. Monitoring embryo development in chicken eggs using acoustic resonance analysis. Biotechnology Progress, 13(4): 474-478.

Deng, X.; Q. Wang; H. Chen and H. Xie. 2010. Eggshell crack detection using a wavelet-based support vector machine. Computers and electronics in agriculture, 70(1): 135-143.

Elmessery, W. M. and S. E. Abdallah. 2014. Manufacture evolution of a microbial contamination detection unit for processed tomatoes inside food factories. AMA-Agricultural Mechanization in Asia, Africa and Latin America, 45(4): 32-38. 
FAO. 2009. Food and Agriculture Organization of the United Nations. Mapping traditional poultry hatcheries in Egypt. Prepared by M. Ali Abd-Elhakim, Olaf Thieme, Karin Schwabenbauer and Zahra S. Ahmed. AHBL - Promoting strategies for prevention and control of HPAI, Rome.

Faris, D. M. and M. B. Mahmood. 2014. Data acquisition of greenhouse using Arduino. Journal of Babylon University/Pure and Applied Sciences, 22(7): 1908-1916.

Hai-ling, L.; C. AiJian-rong; S. Li; Y. Lei-ming and L. Meng-le. 2016. Research on the discrimination of hatching eggs activity based on thermal imaging: A food nondestructive testing practice. International Journal of Smart Home, 10(2): 175-186.

Hopfer, H.; S. E. Ebeler and H. Heymann. 2014. Comparison of different data analysis tools to study the effect of storage conditions on wine sensory attributes and trace metal composition. In: Food informatics. Springer International Publishing, 213-231.

Howe, R. S.; W. W. Burggren and S. J. Warburton. 1995. Fixed patterns of bradycardia during late embryonic development in domestic fowl with $\mathrm{C}$ locus mutations. American Journal of Physiology-Heart and Circulatory Physiology, 268(1): H56-H60.

Johnson, G. W. and R. Jennings. 2006. LabView graphical programming. 4th Ed., McGraw-Hill, New York, USA.

Jones, S. T.; R. E. Shattuck and A. I. Center. 2005. Detection of Early Embryonic Development in hatching eggs: a hyper spectral imaging systems and neural network approach. Johns Hopkins APL Technical Digest, 1: 67-73.

Kato, K.; K. Moriya; E. Dzialowski; W. W. Burggren and H. Tazawa. 2002. Cardiac rhythms in prenatal and perinatal emu embryos. Comparative Biochemistry and Physiology Part A: Molecular \& Integrative Physiology, 131(4): 775-785. 
Klein, S.; M. Rokitta; U. Baulain; J. Thielebein; A. Haase and F. Ellendorff. 2002. Localization of the fertilized germinal disc in the chicken egg before incubation. Poultry science, 81(4): 529-536.

Liang, S.; J. Liu; Z. S. Zhang and X. Li. 2011. Monitoring of live chick embryo based on acoustic and vibration signals with a new semiinvasive technology. Australian Journal of Agricultural Engineering, 2(5): 127-131.

Lin, H.; J. W. Zhao; Q. S. Chen; J. R. Cai and P. Zhou. 2009. Eggshell crack detection based on acoustic impulse response and supervised pattern recognition. Czech Journal of Food Science, 27(6): 393-402.

Liu, L and M. O. Ngadi. 2013. Detecting fertility and early embryo development of chicken eggs using near-infrared hyper spectral imaging. Food and Bioprocess Technology, 6(9): 2503-2513.

Maranhão, G. N. D. A.; A. U. Brito; A. M. Leal; J. K. S. Fonseca and W. N. Macêdo. 2015. Using LDR as sensing element for an external fuzzy controller applied in photovoltaic pumping systems with variable-speed drives. Sensors, 15(9), 24445-24457.

Moriya, K.; J. T. Pearson; W. W. Burggren; A. Ar and H. Tazawa. 2000. Continuous measurements of instantaneous heart rate and its fluctuations before and after hatching in chickens. Journal of Experimental Biology, 203(5): 895-903.

Moriya, K.; J. Höchel; J. T. Pearson and H. Tazawa. 1999. Cardiac rhythms in developing chicks. Comparative Biochemistry and Physiology Part A: Molecular \& Integrative Physiology, 124(4): 461-468.

Narushin, V. G. and M. N. Romanov. 2002. Egg physical characteristics and hatchability. World's Poultry Science Journal, 58:297-303.

Nurdiyah, D. I. A. M. 2016. Comparison support vector machine and knearest neighbor for classification fertile and infertile eggs based on GLCM texture analysis. Journal Transformatika, 13(2): 29-34. 
Önler, E.; I. H. Çelen; T. Gulhan and B. Boynukara. 2017. A study regarding the fertility discrimination of eggs by using ultrasound. Indian Journal of Animal Research, 51(2): 322-326.

Pradeep, K. P. J.; K. S. P. Reddy; D. H. Kumar; K. N. Raju and C. Nagaraja. 2014. Monitoring of temperature and humidity using LIFA. International Journal of IT, Engineering and Applied Sciences Research (IJIEASR), 3(6): 1-3.

Smith, D. P.; K. C. Lawrence and G. W. Heitschmidt. 2008. Fertility and embryo development of broiler hatching eggs evaluated with a hyper spectral imaging and predictive modeling system. International Journal of Poultry Science, 7(10): 1001-1004.

Sun, J.; S. L. Cong; H. P. Mao; X. Zhou; X. H. Wu and X. D. Zhang. 2017. Identification of eggs from different production systems based on hyperspectra and CS-SVM. British poultry science, 1-6.

Tazawa, H.; H. Mitsubayashi; M. Hirata; J. Höchel and J. T. Pearson. 1999. Cardiac rhythms in chick embryos during hatching. Comparative Biochemistry and Physiology Part A: Molecular \& Integrative Physiology, 124(4): 511-521.

USDA. 2006. Poultry: Chickens and eggs. United States Department of Agriculture, National Agricultural Statistics Service (NASS), Washington, DC.

Yongwei, W.; J. Wang; B. Zhou and Q. Lu. 2009. Monitoring storage time and quality attribute of egg based on electronic nose. Analytica Chimica Acta, 650(2): 183-188.

Zhao, J.; H. Lin; Q. Chen; X. Huang; Z. Sun and F. Zhou. 2010. Identification of egg's freshness using NIR and support vector data description. Journal of food Engineering, 98(4): 408-414.

Zhihui, Z.; L. Ting; X. Dejun; W. Qiaohua and M. Meihu. 2015. Nondestructive detection of infertile hatching eggs based on spectral and imaging information. International Journal of Agricultural and Biological Engineering, 8(4): 69-76. 
Zhu, Z. and M. Ma. 2011. The identification of white fertile eggs prior to incubation based on machine vision and least square support vector machine. African Journal of Agricultural Research, 6(12): 26992704.

الملخص العربي

جهاز كثف جديد منخفض التكلفة للتمييز المبكر لخصوبة البيض بيض إنفائل باستخدام مصنفات إحصائية متقدمة المبلة

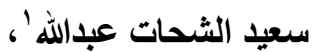

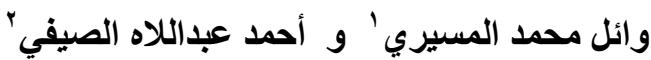

تعتبر عملية إستبعاد البيض غير القابل للفقس قبل عملية التحضين من أعقد العمليات نتيجة لعدم

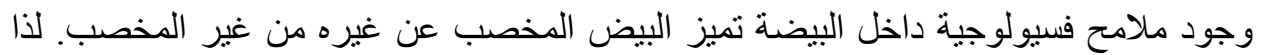

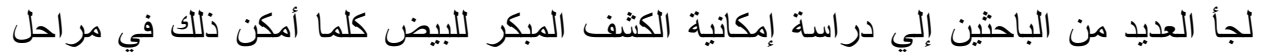

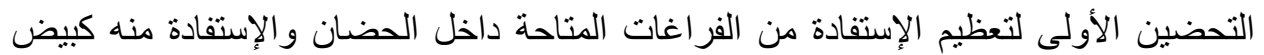

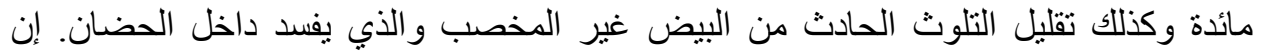

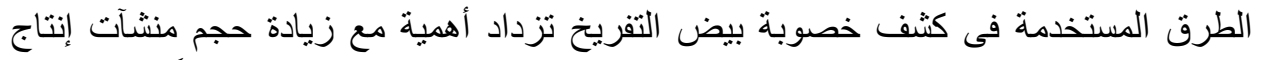

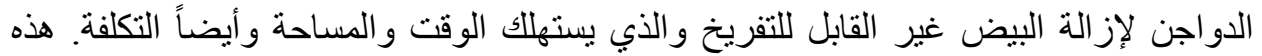

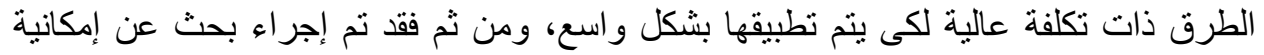

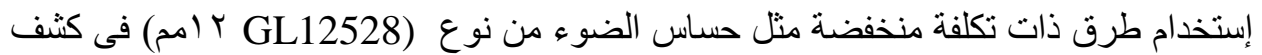

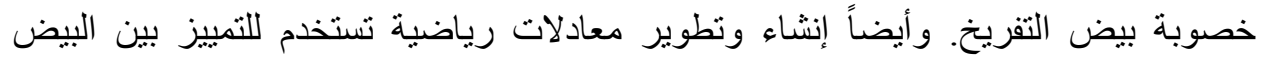
المخصب و غير المخصب، وبو اسطة هذه المعادلات يمكن توصيل حساس الضو و بن بنظم تحكم مثل

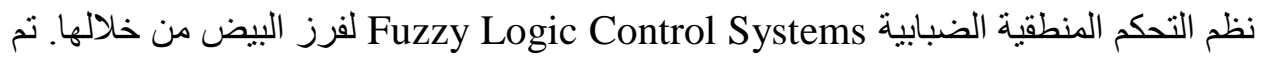

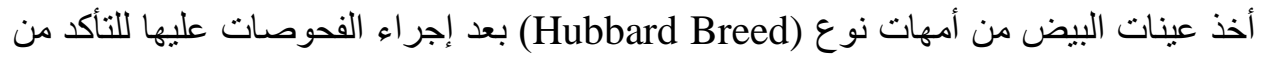

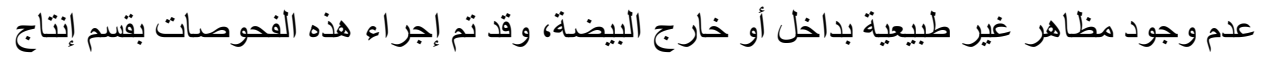

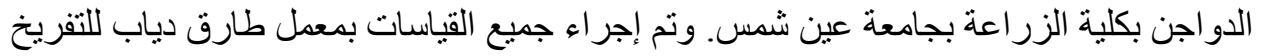

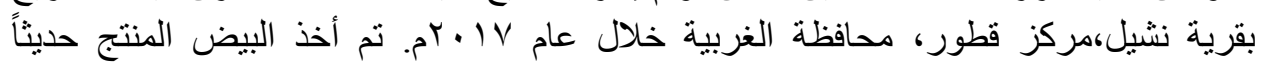
ووضعه في حضانات من نوع:

Smart ${ }^{\mathrm{TM}}$ (Pas Reform Hatchery Technologies, Zeddam, the Netherlands)

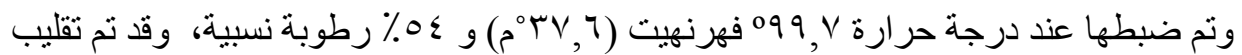

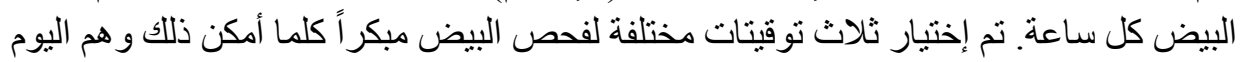
السادس و التاسع و الثاني عشر من بداية عملية التحضين.

1- أستاذ هندة التصنيع الزراعي المساعد ـ قسم الهندسة الزراعية ـ كلية الزراعة ـ ـ جامعة كفر الثيخ

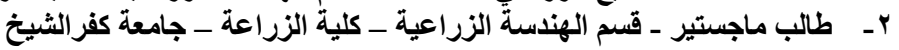




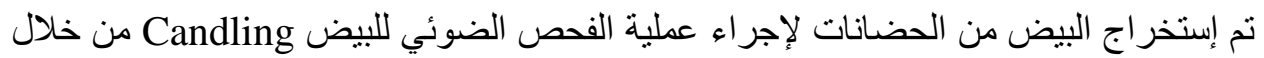

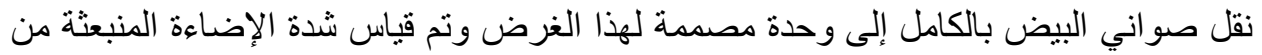
كل بيضة بواسطة حساس الضوء لكل مرحلة من مراحل التحضين سابقة الذكر، وفي ثلاثلة

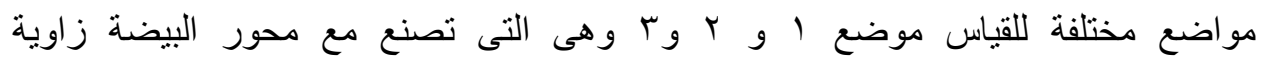

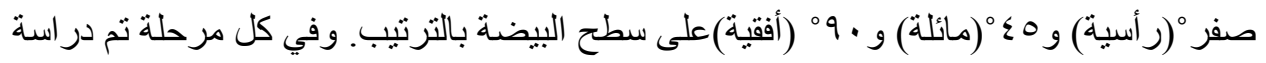

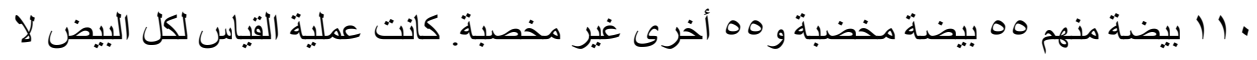
تتجاوز الدقبقتين للحفاظ على حياة الأجنة داخل البيض.

تم إدخال البيانات المتحصل عليها لبرنامج 2017 XLSTAT للتعرف على كلى كفاءة حساس

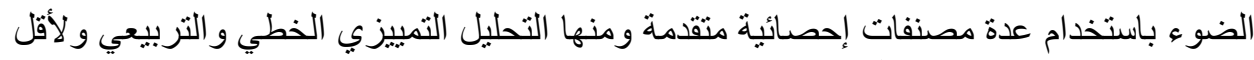

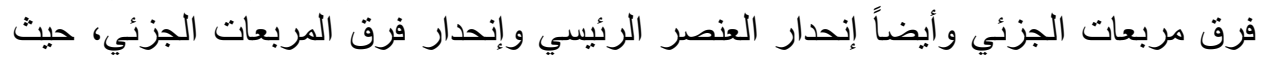

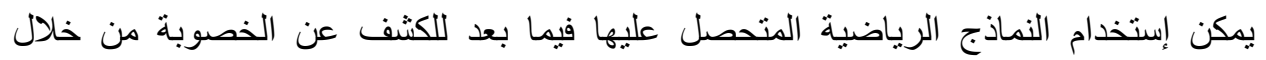

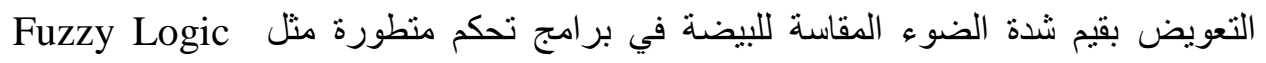
كادة Control System

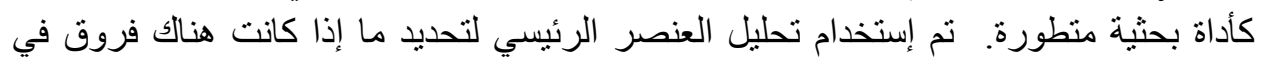

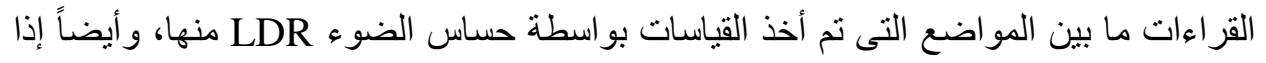

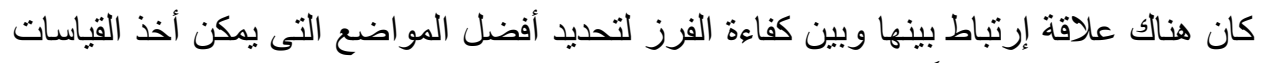

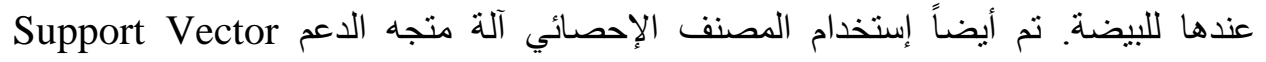

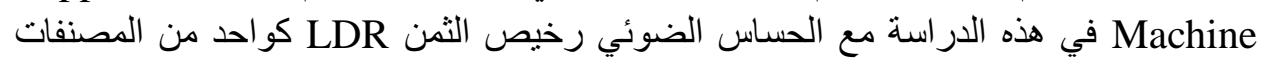

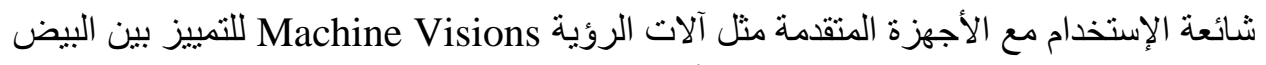

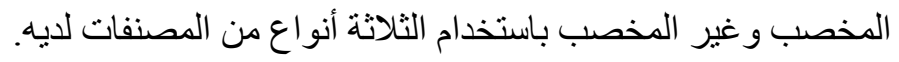

\section{وقد تم التوصل لأهم النتائج الآتية:-}

r GL12528)

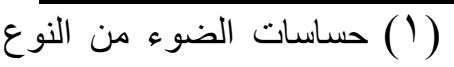

كثف خصوبة بيض التفريخ.

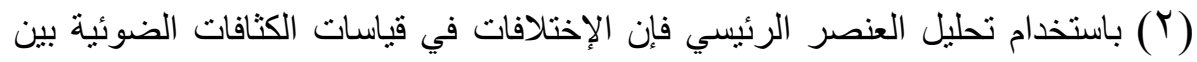

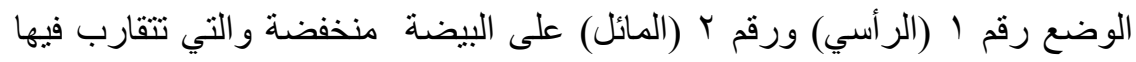

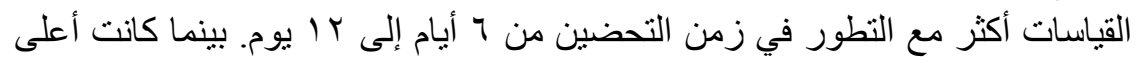

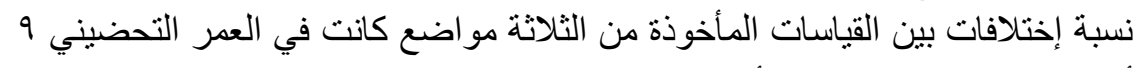

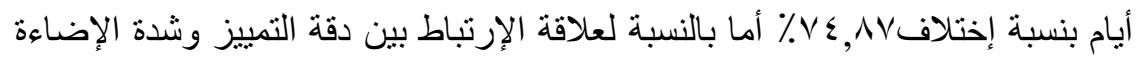

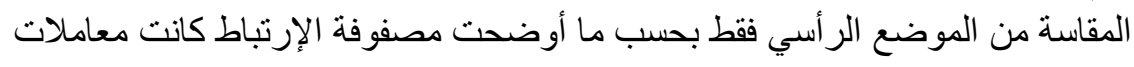

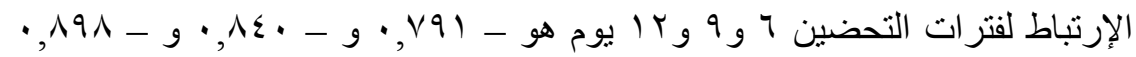

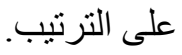

(r) النماذج الرياضية المطورة باستخدام التحليل الإنحداري للعنصر الرئيسي PCR و لأقلى

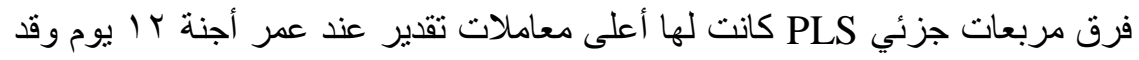

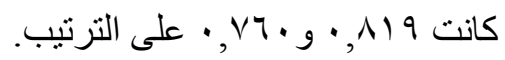


( ) أما بإستخدام المصنفات الإحصائية المتقدمة، نم التوصل إلى أعلى دقة في التمبيز عن

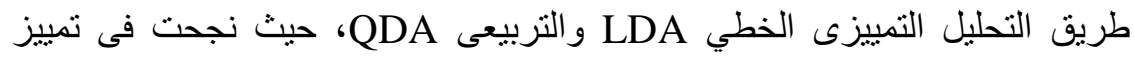
البيض المخصب عن غيره من غير المخصب عند عمر تحضيني 7 أيام بنسبة فئن و 90\% على الترتيب، وذللك لمجموعة البيانات المستخدمة فى إجراء التصنيف

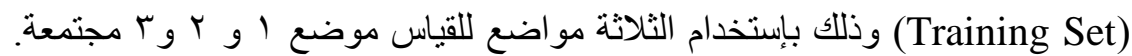

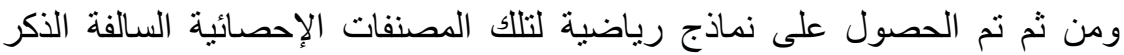
لاستخدامها فى تحديد خصوبة البيض من نوع (Hubbard Breed) من خلاذلة الإل التعويض فيها بشدة الإضـاءة المقاسة.

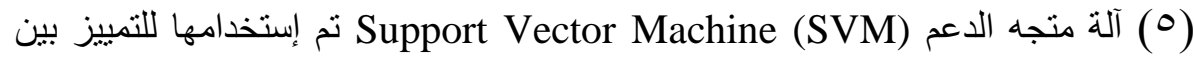
البيض بحسب الخصوبة للانواع الثلاثة المستخدمة ) Linear, Power and RBF

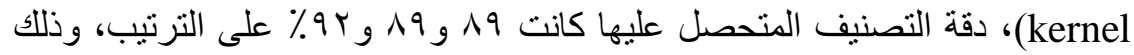

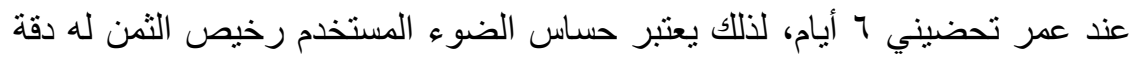

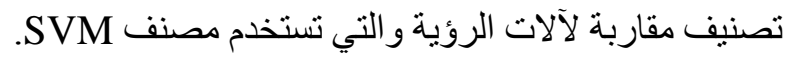

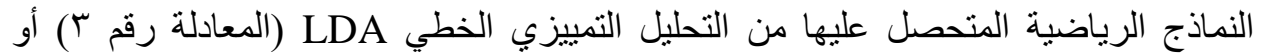

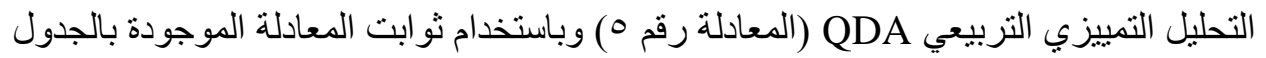

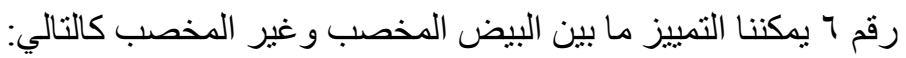
المعادلة رقم ץ (المعادلة الخاصة باختبار البيض المخصب): $f=a+b I_{1}+c I_{2}+d I_{3}$

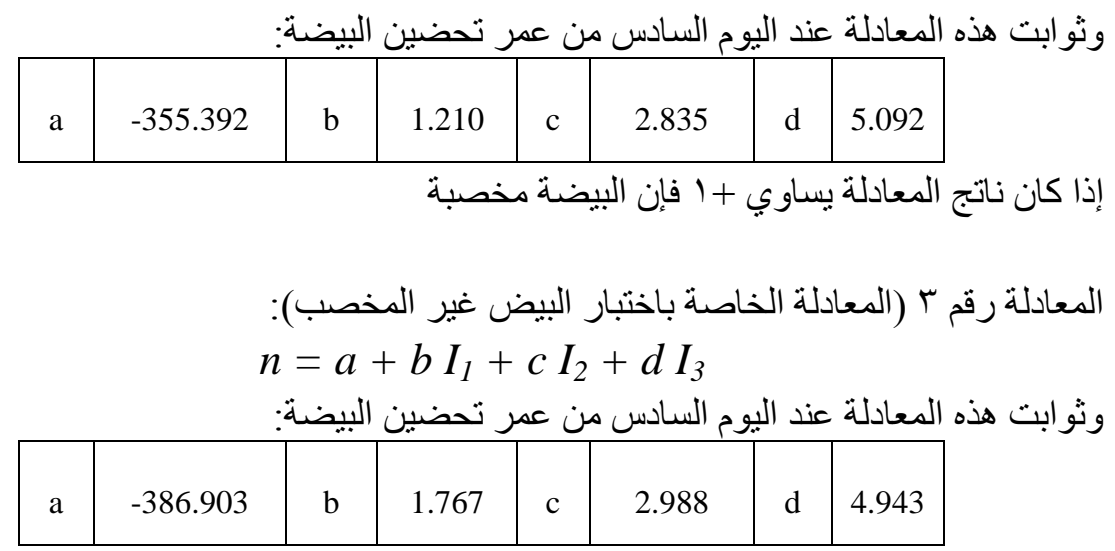

إذا كان ناتج المعادلة يساوي ــ إنان البيضة غير مخصبة

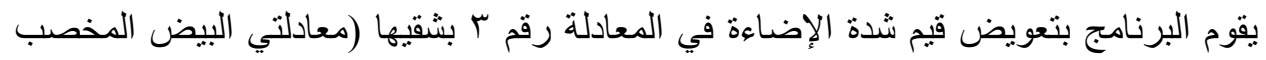

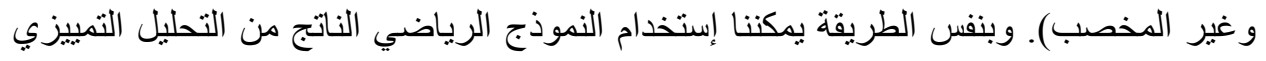
التربيعي وكذللك للعمر المحدد للجنين. 